Journal of

Food and Nutrition

\title{
Scurvy: A New Old Cause of Skeletal Pain in Young Children
}

\section{Christel Chalouhi ${ }^{1}$, Nayla Nicolas ${ }^{2}$, Nancy Vegas ${ }^{1}$, Soraya Matczak ${ }^{1,3}$, Houmam El Jurdi ${ }^{1}$,Nathalie Boddaert ${ }^{2,3}$,} Véronique Abadie ${ }^{1,3^{*}}$

${ }^{1}$ General pediatrics department, Necker Hospital, Paris, France

${ }^{2}$ Pediatric Imaging Unit, Necker Hospital, Paris, France

${ }^{3}$ University of Paris - Faculté de Médecine Paris Descartes, Paris, France

*Corresponding author: Véronique Abadie, Pediatrics General Service and Infectious Diseases, Necker Hospital, 149 rue de Sèvres, 75015 Paris, Tel: 0033144495211; Fax: 0033144381750; E-mail: veronique.abadie@aphp.fr

Received Date: September 06, 2019 Accepted Date: October 22, 2019 Published Date: October 24, 2019

Citation: Christel Chalouhi (2019) Scurvy: A New Old Cause of Skeletal Pain in Young Children. J Food Nutr 5: 1-7.

\begin{abstract}
We report 3 cases of scurvy in children that occurred during a short periodof time (2018) in a general pediatrics unit of a tertiary hospital for children in Paris. All the children were around 3 years of age and were admitted for skeletal pain and altered general state, which mimicked infectious or malignant diseases. Their selective diet was not the prominent issue. The diagnosis of scurvy was delayed, after too many unnecessary examinations and medications. Bone imaging (X-ray and MRI) was a posteriori considered typical, but lesions were not easily identified as scurvy lesions because scurvy is not well known by pediatricians and radiologists who should be mindful of this historical diagnosis.
\end{abstract}

Keywords: vitamin C, ascorbic acid, scurvy, selective diet

(C)2019 The Authors. Published by the JScholar under the terms of the Creative Commons Attribution License http://creativecommons.org/licenses/ by/3.0/, which permits unrestricted use, provided the original author and source are credited. 


\section{Introduction}

Modern-day physicians tend to consider scurvy a disease of the past, first described in ancient times, as illustrated by the writings of Hippocrates (460 BC): “... the breath smells bad, the gums separate from the teeth, blood runs from the nostrils, black-colored ulcerations frequently appear on the legs, some heal others do not, and the skin is thin...". Likewise, in the writings of Jean de Joinville, counselor to Louis XI, dating back to the Seventh Crusade fought in Egypt in 1248, and, more familiarly, descriptions by the great navigators during the Renaissance. Jacques Henri Bernardin de St Pierre, aboard an East India Company ship in 1768, wrote: "the first sign of scurvy is general lethargy: the patient craves rest; feels disgruntled; is sickened by everything; suffers during the day; only finds solace at night; then red dots appear on the legs and chest and bleeding ulcers appear on the gums. Frequently there are no outward signs at all, but the slightest cut remains incurable while we are at sea and progresses most rapidly. I sustained a slight cut to the end of my finger. Within 3 weeks the wound had ravaged the whole finger and had already spread to my hand despite all attempts to heal it. Several days after I had reached my destination it healed of its own accord." In 1747, aboard the Salisbury, the surgeon James Lind undertook what is considered one of the first clinical trials: 12 patients with scurvy were administered different remedies, yet only those fed lemon juice recovered [1-3].

The literature contains accounts of vitamin C deficiency in impoverished countries, notably a review published in Thailand in 2003 describing 28 children (mean age 29 months) with a diagnosis of scurvy, who had been fed a diet of ultra-high-temperature pasteurized milk combined with cooked meat and starchy food but no fresh fruit or vegetables [4]. The same year, a non-governmental organization reported a hemorrhagic fever epidemic in Afghanistan that in fact proved to be a scurvy outbreak [5]. Despite thisknowledge, a scurvy outbreak recently occurred in a refugee camp in Kenya in 2018 [6].

In developed countries, scurvy is rare and mainly described in children with autism or neurological problems. Here we present three cases that occurred during the same year, 2018, in children presenting to the general pediatrics unit of a tertiary hospital in a socially advantaged district of Paris, in children with no special needs.

\section{Case 1}

A 3-year-old boy was admitted to the hospital forstunted growth, regression of walking, eating disorders and behavior troubles. Hewas exclusively breastfed for the first 12 months of his life, during which the transition to bottle-feeding with formula milk was unsuccessful. Therefore, breast feeding was continued until 22 months of age, combined with an undiversified diet consisting of stewed fruits and dairy products. His initial psychomotor development was normal, but he became introverted and with excessive irritability gradually from 2 years of age. His diet became more and more selective. During his third yearof life, his growth rate had slowed. He sustained recurrent ear-nose-throat infections. One month before admission, his general condition had deteriorated; he was dejected and increasingly reluctant to walk, retreating into withdrawal behavior and playing somewhat repetitive games. After the boy was admitted to our department, we observed evidence of a malnourished, very anxious, rather dejected child, refusing to walk, who ateonly bread and goat's cheese. Clinical examination revealed conjunctival hyperemia involving bleeding from the lateral angle of the eye and somewhat swollen, erythematous gums that we attributed to an intercurrent viral infection. The initial suspected diagnosis was malignant disease and autism spectrum disorder. The septic workup was negative. Lower-limb radiographs revealed osteoporosis that was more pronounced in the metaphyses, with an eroded appearance of the tibial plateau and clear bands on the distal extremity of the femur (Figure 1). We searched for consequences of his selective diet, but did not a priori think that all his symptoms could match scurvy. His nutritional assessment revealed low ferritin level and null plasma vitamin $\mathrm{C}$ content. On this basis, classical scurvy involving gingivitis, conjunctival hemorrhage and bone damage was diagnosed. Vitamin $\mathrm{C}$ treatment was rapidly effective. The boy regained motor function and his general condition greatly improved. The diagnosis of autism spectrum disorder was ruled out. Cognitive assessment was unremarkable. Treatment for behavioral and speech disorders was effective within several months.

\section{Case 2}

A 3.5-year-old girl was admitted to hospital for pain on walking and persistent crying. She was the first child of healthy parents. Her appetite was low, yet growth was normal and her parents reported no restrictive eating behavior. Development was normal until 2 years of age, but for 6 months, she had been repeatedly complaining of leg pain and had temporary limping that on one occasion was attributed to transient synovitis and on another to growing pains. Two months before admission, the girl was increasingly fatigued and irritable. She complained of pain in her left knee. Loss of appetite was reported. Her diet had become increasingly selective, consisting of starchy food, dairy 


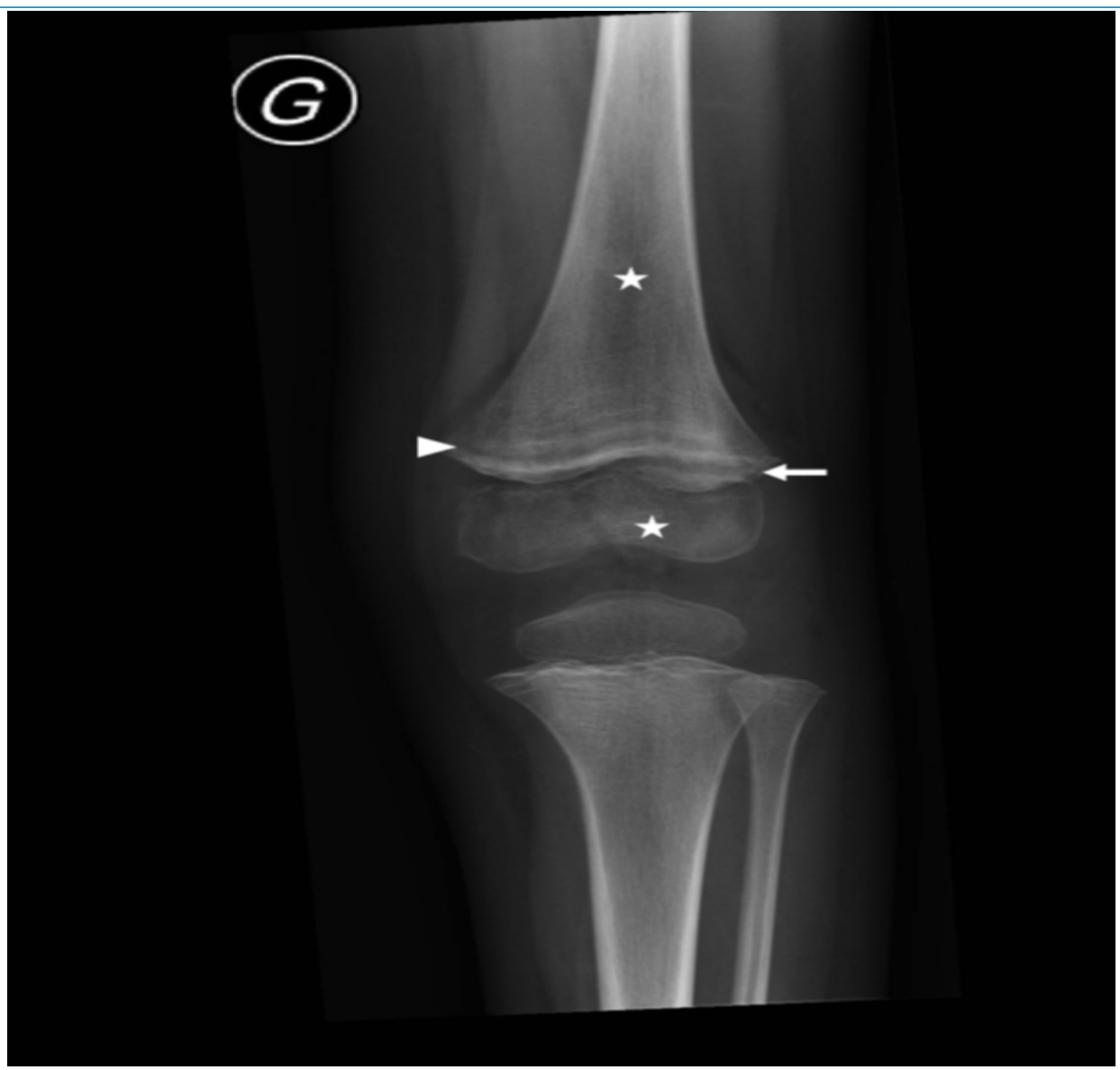

Figure 1: Left knee radiograph demonstrating multiple clear metaphyseal bands in the distal femur (white arrow head) associated with irregular and enlarged metaphyseal margin (white arrow). Diffuse osteopenia (stars) is also noted.

products and bread. After the girl was admitted to hospital, we observed an introverted, anxious child who was prone to tears and easily distressed, especially when approached or touched. Objective assessment was normal in all other respects. Osteomyelitis was initially suspected despite no biological inflammatory reaction. The girl received an 8-day course of antibiotics, with tearful outbursts each time a blood sample was taken. In light of persistent signs and a negative septic workup, malignant disease was suspected. Also, leukemia was suspected. However, bone-marrow aspiration was normal. Initial radiograph findings showed mild vertebral osteopenia at T11, and MRI revealed diffuse lesions affecting the femoral extremities (Figure 2). We suspected a chronic recurrent multifocal osteomyelitis and started anti-inflammatory treatment. During a staff meeting when the case was presented, the physician who had taken care of the first case described above evoked scurvy. Plasma vitamin C contentwas severely deficient. Vitamin $C$ treatment resulted in rapid reduction of all symptoms. Anamnesis subsequently revealed a highly selective diet that had been neglected by the parents who were more concerned about their daughter's orthopedic problem.

\section{Case 3}

A 3-year-old girl was admitted to hospital for functional impairment in both lower limbs, with fever and deteriorated general physical condition. She was a twin, born at 34 weeks' gestation. Because of the parents' inadequate care, she and her sister were placed in foster care at birth, where they remained until age 7 months, when were returned to their family. Their development was satisfactory for the first year of life, but then the patient progressively developed an eating disorder, becoming selective and exhibiting poor language development. For the language deficiency and poor motor skills, a neurological evaluation was undertaken and cerebral MRI was requested, with no remarkable findings. The girl would eat only a particular brand of creamy yogurt and a brand of mixed baby food. Quantities were adequate, so her growth was correct. At 8 days before admission, she was seen for lower-limb pain, fever and an inability to walk. Tests searching for infection yielded negative findings and the girlwas discharged with a diagnosis of probable viral disease. The parents returned 3 days later because of persistent symptoms. The girl was admitted for evaluation. We observed an introverted, very unsociable and apprehensive little girl, who lay flat in her stroll- 


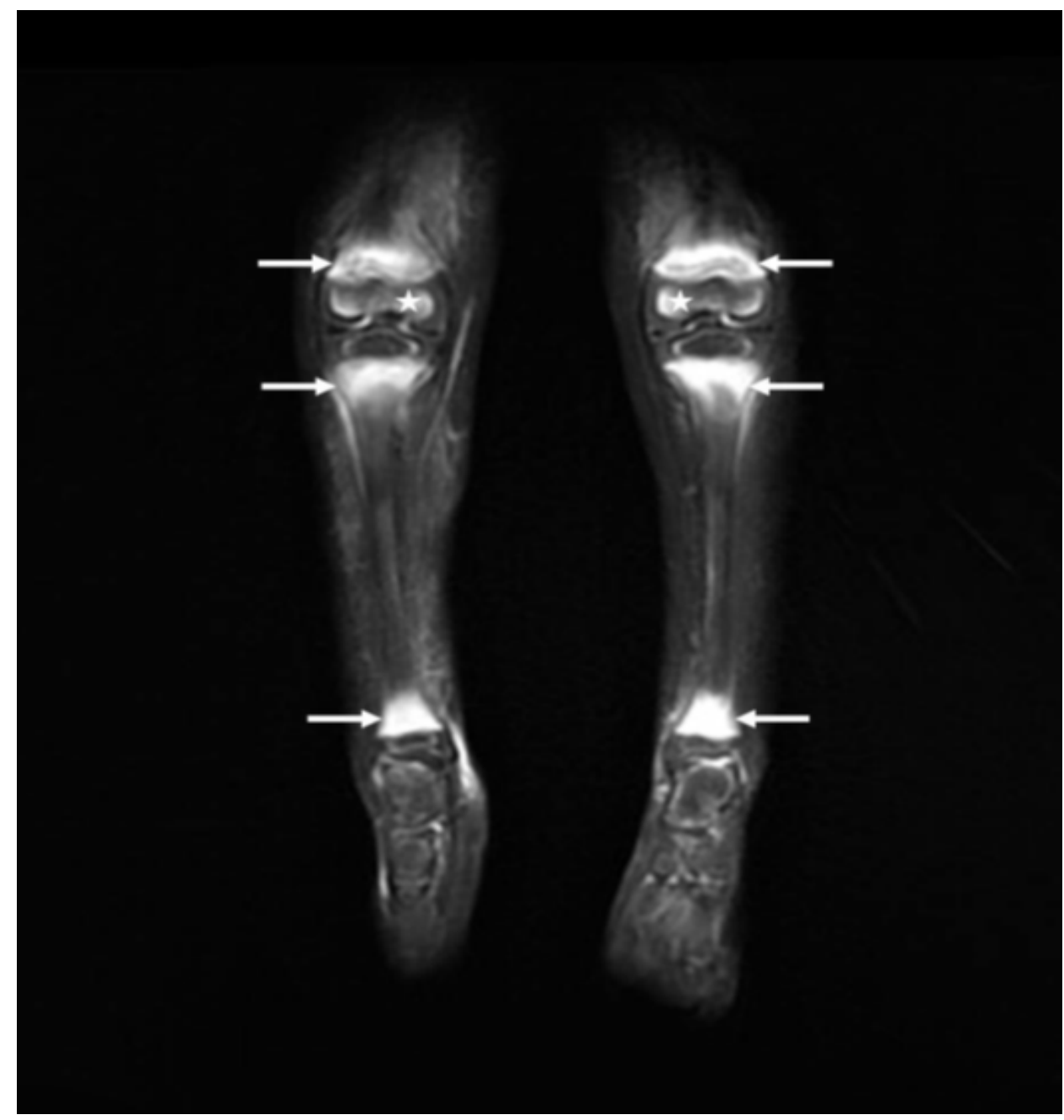

Figure 2: Bilateral lower leg MRI: coronal fat-suppressed T2-weighted image revealing bilateral intra-osseous edematous changes of the metaphyseal area (white arrows) of the ankles and knees. Edematous changes were also noted in the distal epiphysis of the femur bilaterally (stars). Whole-body MRI of this patient shows multiple similar anomalies in the wrists and shoulders.

er and with whom it was difficult to communicate. She had dry skin and inflammatory hair follicles. Laboratory tests showed no inflammatory reaction. Bone radiographic findings were unremarkable; however, MRI revealed multifocal hemorrhagic lesions that in this case were suspected as attributable to scurvy (Figure 3). Plasma vitamin C content was severely deficient. As for the previous cases, within days, vitamin $C$ treatment had a positive effect on pain, behavior and motor function. The developmental and language difficulties improved after nutritional and psycho-educational interventions.

\section{Comments}

These 3 cases confirmthat scurvy is a reemerging disease that pediatricians need to consider, especially in the presence of unexplained bone pain, even in children with typical development. These 3 children, especially case 2 , would have had fewer investigations if the diagnosis of scurvy had been mentioned earlier. Doctors must ask about dietary habits, especially in children around 3years of age who are no longer receiving infant formula but who may not yet have a diversified diet.

Vitamin $\mathrm{C}$ or ascorbic acid is an essential vitamin since the occurrence of a genetic mutation inhibiting the conversion of glucose to ascorbic acid in primates 40 million years ago madehumans dependent on an exogenous supply of vitamin $C$. This enzyme is still present in most mammals [7-8]. Vitamin $C$ is very actively absorbed by the ileum, and rapidly eliminated by renal excretion. With excessive intake, it is absorbed passively and also excreted renally with no risk of overdose. However, insufficient intake owing to low reserves results in onset of biological deficiency within 3 months and clinical signs within 6 months [9]. Ascorbic acid plays a critical role in the formation of type II collagen, and deficiency accounts for bone and vessel wall lesions. Ascorbic acid has antioxidant and anti-infection properties and enhances iron absorption and heavy metal detoxification [10]. 


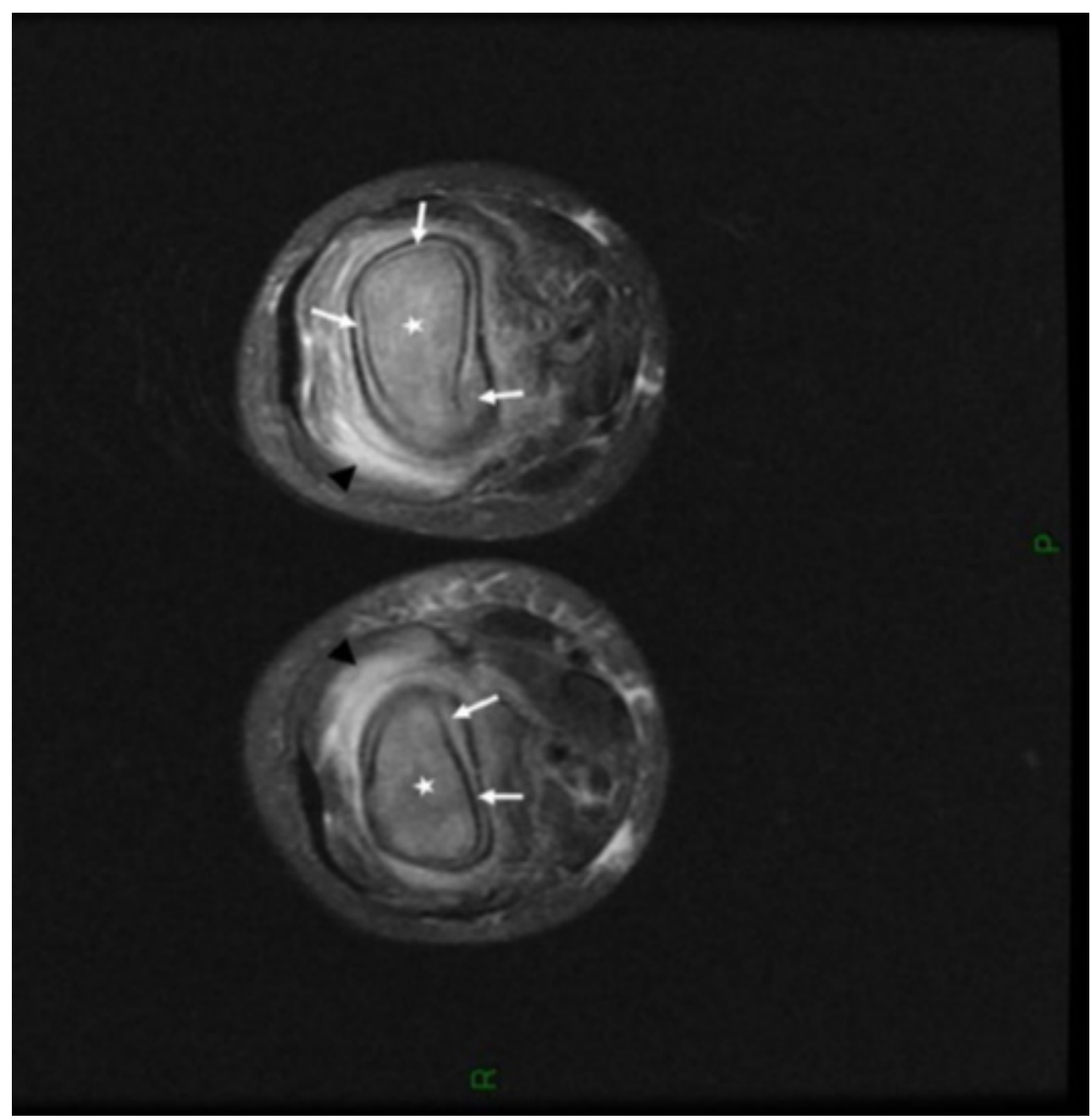

Figure 3: Bilateral knee MRI: axial fat-suppressed T2-weighted image showing important bilateral edematous changes within (stars) and around the bone (black arrowheads) associated with bilateral circumferential subperiosteal collections (white arrows) related to bilateral subperiosteal hematomas.

Classical signs of scurvy include gingival lesions together with inflammation, hypertrophy and loosened teeth resulting from bleeding. Oral lesions accentuate anorexia, leading to food selectivity. Second-stage disorders are of a cutaneous nature, involving dry skin, folliculitis, vascular purpura and hematomas that can be painful, thus accentuating anorexia. Third-stage disorders are of a musculoskeletal nature, involving osteoporosis, bone growth abnormality, and subperiosteal or intraosseous hemorrhagic lesions that mimic inflammatory disease. Fourthstage disorders affect the general physical condition, with asthenia and dejection that probably also perpetuate eating disorders.

The US recommended daily intake of vitamin C is 15 $\mathrm{mg}$ /day for children 1 to 3 years old, $25 \mathrm{mg} /$ day for those 4 to 8 years old, approximately $50 \mathrm{mg}$ /day for those 8 to 18 years old and $100 \mathrm{mg}$ for adults. The richest food sources of vitamin $\mathrm{C}$ are fruit and vegetables, especially blackcurrants, parsley, peppers, lemons, lychees, strawberries, raspberries, gooseberries, papaya and kiwis [11].

In France as in other developed countries, 3 sets of circumstances can lead to the re-emergence of scurvy. The first represents adults living in highly precarious conditions. The second is children whose selective diet is devoid of fresh fruit and vegetables or stewed fruit. Such eating behaviors may occur in children with autism spectrum disorders or severe neuro developmental disabilities but also in children with aversion restrictive food intake disorders or only selective eating behavior. The third scenario is children fed a diet of vegetable milk such as almond milk or other types of milk popular with vegan parents. About 80 pediatric cases have been published in the past 20 years, essentially occurring in children with autism spectrum and neuro developmental disorders [12-21] but not necessarily [22-24]. Vitamin C deficit is more frequent than classical scurvy, as recently shown by a retrospective review of the files of children with low ascorbic level [25]. Further accounts are available on the Internet 
and in the general press [23].

\section{Conclusion}

Risk of scurvy continues to exist, even in developed countries, in individuals lacking vitamin $\mathrm{C}$ intake for more than 3 to 6 months. Therefore, caution is warranted for all children whose eating habits for whatever reason are selective.Vitamin C must be given as orange juice or vitamin supplements. Scurvy symptoms should be known to pediatricians. Similarly, pediatric radiologists should be mindful of scurvy, given that presentations frequently mimic infectious or malignant bone abnormalities.

\section{References}

1. Still G F (1906) A clinical lecture on infantile scurvy Br Med J 2: 186-190.

2. Still GF (1935) Infantile scurvy: its history. Arch Dis Child 10: 211-218.

3. Jacques Henry Bernardin de Saint Pierre - Voyage à l'île de France un officier du roi à l'Ile Maurice (1768-1770) - Merlin - Paris - 1773.

4. Ratanachu-EK S, Sukswai P, Jeerathanyasakun Y, Wongtapradit L (2003) Scurvy in pediatric patients: a review of 28 cases. J Med Assoc Thai, 86 Suppl 3: S734-40.

5. Cheung E, Mutahar R, Assefa F, Ververs MT, Nasiri SM, et al Borrel A (2003) An epidemic of scurvy in Afghanistan: assessment and response.Food Nutr Bull 24: 247-255.

6. Ververs M, Muriithi JW, Burton A, Burton JW, Lawi AO (2019) Scurvy Outbreak Among South Sudanese Adolescents and Young Men - Kakuma Refugee Camp, Kenya, 2017-2018. Morb Mortal Wkly Rep. 68: 72-75.

7. Montel-Hagen A, Kinet S, Manel N, Mongellaz C, Prohaska R et al (2008) Red cell GLUT1 compensates for the lack of vitamin C synthesis in mammals. Med/Sci 24: 434-436.

8. Yang H (2013) Conserved or lost: molecular evolution of the key gene GULO in vertebrate vitamin C biosynthesis. Biochem Genet 51: 413-425.

9. Jacob R. Vitamin C.In: Shils M, Olson J, Shike M, Ross AC, eds. (2000) Modern Nutrition in Health and Disease. Philadelphia, PA: Lippincott :467
10. Figueroa-Mendez R and Rivas-Arancibia S (2015) Vitamin C in Health and Disease: Its Role in the Metabolism of Cells and Redox State in the Brain. Front Physiol, 6, Article 397: 1-11.

11. Olson JA, Hodges RE (1987) Recommended dietary intakes (RDI) of vitamin C in humans. Am J Clin Nutr 45: 693-703.

12. Agarwal A, Shaharyar A, Kumar A, Bhat MS, Mishra M (2015) Scurvy in pediatric age group - A disease often forgotten? J Clinn Orthop Trauma 6: 101-107.

13. Swed-Tobia R, Haj A, Militianu D, Eshach O, Ravid S, et al. (2019) Highly Selective Eating in Autism Spectrum Disorder Leading to Scurvy: A Series of Three Patients. Pediatr Neurol 94: 61-63.

14. Ceglie G, Macchiarulo G, Marchili MR, Marchesi A, RotondiAufiero L, et al. (2019) Scurvy: still a threat in the wellfed first world? Arch Dis Child 104: 381-383.

15. Rafee Y, Burrell K, Cederna-Meko C (2018) Lessons in early identification and treatment from a case of disabling vitamin $\mathrm{C}$ deficiency in a child with autism spectrum disorder. Int J Psychiatry Med 54: 64-73.

16. Kinlin LM, Blanchard AC, Silver S, Morris SK (2018) Scurvy as a mimicker of osteomyelitis in a child with autism spectrum disorder. Int J Infect Dis 69: 99-102.

17. Burhop J, Gibson J, de Boer J, Heydarian C (2018) Do You C What I C: Emergency Department Evaluation and Diagnosis of Pediatric Scurvy in an Autistic Child With a Restricted Diet. Pediatr Emerg Care.

18. Planerova A, Philip S, Elad S (2017) Gingival bleeding in a patient with autism spectrum disorder: A key finding leading to a diagnosis of scurvy. Quintessence Int 48: 407-411.

19. Seya M, Handa A, Hasegawa D, Matsui T, Nozaki T (2016) Scurvy: From a Selective Diet in Children with Developmental Delay. J Pediatr 177: 331.

20. Ma NS, Thompson C, Weston S (2016) Brief Report: Scurvy as a Manifestation of Food Selectivity in Children with Autism. J Autism Dev Disord 46:1464-1470.

21. Khan N, Furlong-Dillard JM, Buchman RF (2015) Scurvy in an autistic child: early disease on MRI and bone scin- 
tigraphy can mimic an infiltrative process. BJR Case Rep; 1 : 20150148.

22. Cain M, Harris M, Kim K, and Homme JH (2014) Ascorbic Acid Deficiency (Scurvy) in a Toddler With Restricted Dietary Intake Presenting With "Leg Weakness" and a Rash. Infant, Child, \& Adolescent Nutrition 6: 201-204.

23. Brambilla A, Pizza C, Lasagni D, Lachina L, Resti M, and Trapani S (2018) Pediatric Scurvy: When Contemporary Eating Habits Bring Back the Past. Front Pediatr 6:126.

24. Hahn T, Adams W, Williams K (2019) Is vitamin C enough? A case report of scurvy in a five-year-old girl and review of the literature. BMC Pediatrics $74: 2-6$.

25. Golriz F, Donnelly LF, Devaraj S, Krishnamurthy R (2017) ModernAmerican scurvy - experience with vitamin C deficiency at a large children's hospital 47: 214-220.

26. Marc Azlan (2018) Le Journal Le Monde .https://www. lemonde.fr/blog/realitesbiomedicales/2018/09/09/le-retour-duscorbut-une-maladie-que-lon-croyait-disparue/ 